\title{
Maria Tereza: um corposolo em ruídos e negrices
}

\author{
Fabiana Oliveira de Jesus*
}

\section{Resumo}

Este texto tem o propósito de apresentar a trajetória da poetisa paulistana Maria Tereza, escritora de três livros: Ruídos, Negrices em Flor e Vermelho. Nesta apresentação, damos foco à representação do corpo negro feminino exposto nos versos e à multiartista, que insere, na escrita, sua leitura do mundo feita por seus olhos negros. Escrita esta que elege seus precursores, mostrando suas leituras de mulheres pretas e contando, através de seus versos, sua escrevivência. Revelando, assim, sua ancestralidade e dando voz, através da sua poesia, às mulheres negras que vieram antes para abrir espaço para as que a vieram depois. Sua escrita, é aqui tratada como personificação de seu corposolo.

Palavras Chave: Maria Tereza. Mulher Negra. Escrita. Poesia. 


\section{Maria Tereza: a Solo-Body in Noise and Blackness}

\section{Abstract}

This essay aims to present the trajectory of the São Paulo poet Maria Tereza, writer of three books: Ruídos (Noises), Negrices em Flor and Vermelho (Red). In this presentation, the focus is on the representation of the female black body exposed in the verses, and on the multiartist, who inserts, in her writing, the perception of the world through her afro brazilian eyes. Her writing chooses its precursors, showing its readings of black women and telling, through its verses, its escrevivência ${ }^{1}$. Revealing then, her ancestry and giving voice, through her poetry, to the black women who came before her and made room for those who came after. Finally, her writing is the embodiment of her solo body.

Keywords: Maria Tereza. Black Woman. Writing. Poetry.

Recebido em: 30/09/2020 // Aceito em: 01/12/2020 
Diásporas são partes que caminham ou navegam e voam saindo dum mesmo corposolo e multiplicam e se juntam para retransmitir o primeiro toque, aqui nesse caso, com muita força de resistência, tambores em vozes dinâmicas, conhecimento de vida, formas de amor, liberdades, primitivismo artístico, refinamento ecológicos espirituais, conexões de integração.

Diásporas, negrices, inteligências. Vida verdadeira agora! (TEREZA, 2007, p. 29)

O corpo feminino negro, como a escritora Maria Tereza reflete, é um corpo herdeiro da diáspora africana, que é pensada aqui como essas partes que caminham em um mesmo chão, dinamizando sua sabedoria resistente através de seu corpo. Este corpo é resultado da mistura de "MEU PAI BAIANO, MINHA MÃE PAULISTANA. FILHOS D'ÁFRICA COM ÍNDIOS DO BRASIL" (TEREZA, 2007, p.21 grifo do autor). Fala-se de um corpo pensado, entendido e performatizado na escrita. Ele se manifesta em poemas, ilustrações e, principalmente, na leitura. Pode-se dizer que é um corposolo, ou seja a junção com a obra artística literária: os poemas, as partículas, os glóbulos, a concentração do livro, a corrente sanguínea, o corpo todo, quando o fluxo poético inunda o sistema nervoso da poetisa/ escrita.

Terezinha Taborda Moreira e Jane Quintiliano Guimarães Silva, em artigo intitulado "Escrita e Performance", discutem as formas como a escrita se performa na contemporaneidade. As estudiosas observam que "a contemporaneidade se marca por uma multiplicidade de textualidades e suportes, e em função disso, por uma heterogeneidade de semioses e sentidos" (SILVA; MOREIRA, 2019, p. 7). Ainda segundo as estudiosas, para responder aos apelos do contemporâneo, a escrita 
responde não como mera modalidade da língua, mas como objeto plástico, modo de enunciação movente, tecnologia multimodal, processo, performance, abarcando experimentações multiformes, estéticas ou não. (SILVA; MOREIRA, 2019 p. 7)

Aparentemente a escritora Maria Tereza acredita que o corpo é construído/performatizado pela poesia. Ela, por sua vez, deixa espaço para que o leitor contribua para essa construção, uma vez que seu desenho é feito também ali, naquele instante da leitura, em consonância com a discussão teórica proposta por Silva e Moreira. Parece-nos que essa construção do corpo pela palavra encena a afirmativa de Frantz Fanon, segundo o qual "falar é existir para o outro", pois "existe na linguagem uma extraordinária potência". (FANON, 2008, p. 33). A epígrafe que abre este texto vai além de uma reflexão sobre diáspora, ela é a própria explanação do corposolo, ela é uma síntese da obra de Maria Tereza.

Maria Tereza Moreira de Jesus, atriz, palhaça, poetisa e ilustradora nasceu em 18 de maio de 1974, na cidade de São Paulo, nascida e criada em Vila Nova Cachoeirinha, zona norte da capital. Assinou seus livros com o pseudônimo Maria Tereza. São suas obras que nos contam sua trajetória. Ao tentar ir além de sua obra e buscar informações sobre sua vida pessoal, percebemos que, como várias outras escritoras negras, a história nos escapa, não se propaga. É preciso escavar, procurar a fundo e ter sempre o olhar atento. Até onde nos foi possível conhecer sobre sua trajetória de vida pode-se perceber que Tereza foi uma mulher "sempre atenta quando o tema é pensamento" (TEREZA, 2007, p.33). Participava ativamente da vida sociocultural das periferias da cidade de São Paulo, e era presença ativa em Saraus e oficinas em centros culturais. Ela levava "seu quilombo", que 
em sua ideia é o próprio corpo negro, para a linha de frente da representação negra feminina.

Esse corpo-quilombo é elaborado e nos é apresentado por/ através de sua escrita. Maria Tereza publicou três livros: Ruídos (2002), Negrices em Flor (2007) e o infantil e autobiográfico Vermelho (2009). Compôs uma canção "Mar Interior", gravada por Celso Sim e Rubi, participou de peças de teatro, fez muitas leituras dramáticas e em suas obras vemos nitidamente o forte diálogo com as artes plásticas.

Em uma reportagem da Folha de São Paulo com o título Maria Tereza a Atriz negra que se lançou em alto mar, do dia 30 de abril de 2010, apresenta-se um pouco mais da trajetória artística da escritora, sua trajetória teatral e um trecho de uma canção composta por ela: "Eu vou partir num vapor vulgar/ Vou viajar/ Vou ver estrelas/ E voltar" (TEREZA, 2010). A reportagem foi escrita para comunicar sua morte.

Maria Tereza faleceu em abril de 2010. Um falecimento prematuro, aos 35 anos, provocado por uma rara doença autoimune que, ironicamente, tem o nome de POEMS. Essa síndrome provoca um distúrbio no qual mais de uma glândula endócrina apresenta disfunção e é provavelmente causada por anticorpos que circulam no sangue e danificam os órgãos. A doença segue o fluxo do vermelho líquido que é por onde, segundo Maria Tereza, circula o "fluxo poético" e "inunda o sistema nervoso" (TEREZA, 2007, p.31). A doença atingiu o sangue no qual circula toda ancestralidade, aquela "passadas ao pé do ouvido" como ruídos, "no dentro do vermelho líquido" (TEREZA, 2007, p.28).

Ruídos, seu primeiro livro, é dividido em 52 poemas cujos títulos são números de páginas que vão da página 0 à página 
última: numa forma semelhante a um diário. Há exceções de poemas cujos títulos são: "Ato"; "Velha/preta"; "Pai e Pai"; "Dinheiro"; "Língua"; "Espera" e "Siririca". São "ruídos" que trazem o cotidiano de uma mulher negra contando sobre seu olhar sobre a vida com muito vigor. Uma poesia cujo compromisso não foi estabelecido com apenas uma forma e sim com a simplicidade, o que dá potência e força à obra.

Página trinta e quatro

sei que aqui no brasil diário, o mesmo tanto que nasce, se mata, pelos mesmos porquês que não se cria. Anula. A única via possível. Educação. Sensação só a de fome, desespero e solidão.

Terra de quem?

Ai meu padim,

Quem nasceu pra rapadura dificilmente chega a ser

Só meladim.

[pudim de leite.

A china é do outro lado? Embaixo, debaixo do solo

[rachado?

Produtos somos desidratados.

(TEREZA, 2002, p.99)

Os poemas são apresentados ora em prosa, ora em verso, sem uma regra específica ou, até mesmo, de forma híbrida sem fronteira entre prosa e verso, como é o caso do poema citado acima. Esta é uma marca do trabalho de Maria Tereza: brincar com as formas. No poema acima vemos ainda sua reflexão sobre o Brasil do dia a dia, dentro do dia a dia de Maria Tereza. Ou melhor dizendo, no cotidiano de muitos indivíduos brasileiros, sobretudo, negros. Ruídos é como um diário no qual a poetisa coloca relatos e leituras da sociedade e de si. Essa escolha por fazer uma espécie de diário é uma forma de resgate da leitora que foi. Ao se ler Ruídos, percebe-se que Tereza foi uma grande 
leitora de mulheres pretas. Podemos identificar em sua escrita semelhanças com o também diário Quarto de Despejo: Diário de uma favelada, de Carolina Maria de Jesus. Um escritor escolhe seus precursores e essa relação de Tereza com Carolina Maria de Jesus fica nítida não só no livro em questão, mas percorre toda sua obra:

Página cinco

Diário, impressiona-me esta qualidade que a vida não se aprende na hora. Só depois do momento que se vive, mesmo quando bem dentro dele respirado, obter o fato não me faz dona de mim, respiro durante os intervalos de ser enquanto aqui.

Ter vida e morte atreladas a si.

(TEREZA, 2002, p. 31)

O prefácio de Ruídos é escrito por Fernando Bonassi, escritor e dramaturgo paulista. Ambos se conheceram por ocasião da participação de Maria Tereza em um grupo de dramaturgia que auxiliou na escrita do espetáculo Apocalipse 1,11 (2000), do Teatro da Vertigem. A partir de então começaram a trocar escritos e, segundo ele: (...) "desde o primeiro verso de sua autoria que li, senti a força múltipla desses textos estruturados com extrema sonoridade e ritmo, apontando pras coisas desse mundo a mira fulminante de um olhar ulterino, desbocado e desbun-dado" (BONASSI, 2002 15). E, para assimilarmos melhor as palavras de Fernando Bonassi, lemos o poema "Língua":

\section{Língua}

$\mathrm{O}$ argumento arranha a palavra

Sou o pelo do meu próprio ovo

Ovulo às vezes floresço

Volta e meia sou eu de novo

E se toca lava me lavo 


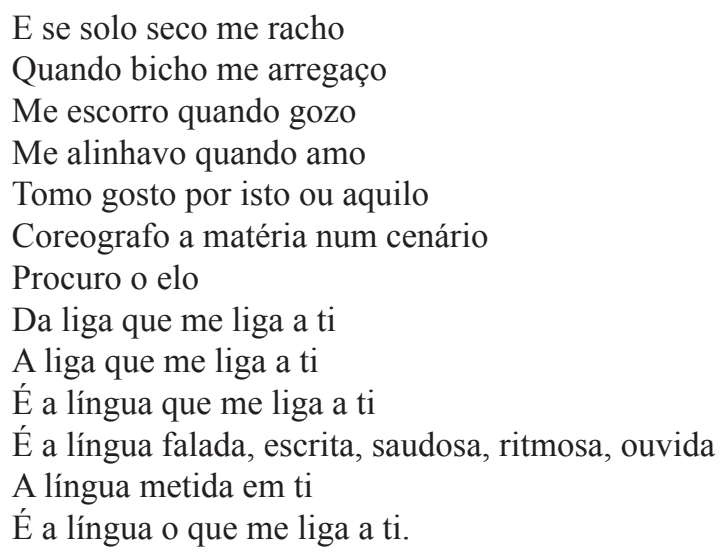

(TEREZA, 2002, p. 89)

Pode-se, nessa leitura do poema, entender como Maria Tereza expõe seu corpo e o deixa disponível para leitura. Como dissemos antes, trata-se de um corposolo exposto como língua viva que se comunica com voz, escrita e ritmo e que se toca e nos toca. Assemelha-se a um solista que se apresenta para cantar uma música a ser ouvida por todos mirando-os de forma fulminante. Ainda segundo Bonassi, a escrita de Maria Tereza representa a fé na arte somada à rebelião. Para ele, a obra de Tereza revela que "não estamos necessariamente condenados à prisão perpétua de nossa própria covardia, pobreza e burrice." Ao fim do seu prefácio intitulado "O Ministério da Saúde adverte...", conclui: "Será preciso acompanhar o trabalho de Maria Tereza... pro nosso próprio bem" (BONASSI, 2002, p. 16).

A poetisa paulistana gostava de ser identificada como poeta, compositora e atriz negra. Era uma multiartista e trabalhava, também, com arte e educação. Conforme posfácio do livro Negrices em Flor (TEREZA, 2007), Maria Tereza revela sobre si o que está exatamente exposto em seus poemas: a relação com a escrita, como podemos ler no poema Língua, a noção do fazer musical e sua inquietude diante da vida. Podemos observar que a 
partir de Negrices em Flor, seu nome é grafado sem sobrenomes, apenas, Maria Tereza.

Maria Tereza, filha de Aparecida Moreira de Jesus e Manoel Adolfo de Jesus, brasileiros evangélicos que a fizeram estudar piano pra tocar na igreja. Reside na Vila Nova Cachoeirinha, zona norte paulistana, onde foi criada com muito amor. Nascida lá pelos inícios da década de 70. Sempre gostou de ler e começou a se interessar pelas artes. Seu primeiro trabalho foi uma leitura dramática de Mistérios Gozozos, de Oswald de Andrade, com Zé Celso. A partir daí, coçou-se muito, e fez oficinas, cursos de danças, de teatro, de dramaturgia, de roteiros, e também de palhaça. Já atuou com textos próprios e com várias gentes. Foi também vendedora e garçonete, recepcionista e até segurança! Agora já madurinha trabalha como arte educadora, se aprimorando para o sustento e pras descobertas junto, nas energias sinceras da criação. Nessa caminhada fez peça infantil, adulta e trabalha com performances poéticas corporais. Participa do Teatro Popular Solano Trindade e do Grupo de Literatura Percussiva e ainda da Cia Causos Negros. Musicou, cantou e encenou poemas de Solano Trindade, Stela do Patrocínio, Hilda Hilst, entre outros. Tem uma canção, Mar interior, gravada por Celso Sim e por Rubi. Publicou Ruidos, em 2004, pela editora ComArte. (TEREZA, 2007, [s.n])

Como muitos artistas brasileiros, Maria Tereza trabalhou em várias áreas para contribuir com seu sustento e com a manutenção de um projeto de vida, o fazer artístico. Ela atuou em trabalhos que fortaleciam não somente a ela, mas que seriam capazes de propagar outras vozes levando a todos um novo olhar, uma nova perspectiva impulsionada pela presença do seu corpo-quilombo.

O livro Negrices em Flor é composto por quarenta e dois poemas da autora. Uma dedicatória onde agradece aos que vieram antes, aos que virão depois, aos orixás, amigos e 
parceiros de edição. E nos recomenda cuidarmos das crianças. Dois poemas do rapper paulistano Gaspar. A composição do livro conta também com ilustrações da própria poetisa. Pela edição da obra percebe-se o cuidado e a delicadeza na criação e elaboração do livro e, na construção da materialidade física do objeto. Ao nos colocarmos diante do livro, ali mesmo, fechado, somos remetidos a um universo distinto do comum: o laço de palha como decoração, a cor da capa, a delicadeza dos traços e o nome. É uma construção delicada, que nos parece ser construída lentamente, “com suor e demora" (TEREZA, 2007, p. 51) como no aprendizado em conta-gotas:

\section{Conta-gotas}

No conta gotas do aprendizado diário, de letrinha com letrinha no passo a passo, a liberdade chegando com suor e demora.

No transporte coletivo de manhã cheiroso, de noite um horror:

Informações e divagações, piadas e muitas broncas, Reclamações

No trabalho a dificuldade de repetir, o sim senhor, a sim senhora.

$\mathrm{Na}$ família a busca eterna pelos laços sempre e Sempre aqui e ali despedaçados.

No barraquinho que morava, todo dia crianças Separando qualquer coisa.

Um pão frito, pedaço de bolo, sorriso dado de Verdade, carinho sem esculacho.

Na mente milimetricamente horizontes alargados.

Dentro do peito um eterno moto-continuo.

Por toda a pele, desejos e sonhos.

(TEREZA, 2007, p. 51)

Assim, o ato de juntar letrinha por letrinha em um processo de alfabetização, que não se resume apenas a formar e ler palavras, revela ao leitor que ajuntar letras e palavras se torna, na verdade, 
a construção de uma ideia elaborada no coletivo para o coletivo. Esse ato transforma-se numa escrita que resiste em dizer "o sim senhor" e manter-se subalternizada às palavras, e deseja juntar os seus familiares, por anos separados continuamente. Nesse processo o significado de família passa a poder ser pensado como comunidade. O verso " $\mathrm{Na}$ mente milimetricamente horizontes alargados" (TEREZA, 2007, p. 51) mostra como o pensamento vai além das limitações sociais a que um povo é condicionado. É de gota em gota que o eu lírico conquista o espaço da fala. É ao contar histórias que ele alcança os sonhos da pele "e faz emergir conhecimentos que sempre existiram e que não encontravam espaço de apreciação, invisibilizados pelos saberes acadêmicos eurocentrados.” (REIS e ANDRADE, 2018, p. 7) Maria Tereza com sua escrita reconstrói "epistemologias autóctones, que foram violentamente destroçadas pelo (neo) colonialismo" (REIS e ANDRADE, 2018, p. 7).

É preciso, portanto, observar a escrita e as histórias contadas hoje pelas mulheres negras, com a intenção de que estas narrativas não se percam no tempo e não haja mais fissura na história da literatura. Observa-se um movimento potente onde podemos verller mulheres negras assumindo um papel cada dia mais constante na escrita, externalizando suas perspectivas e visão de mundo, o que proporciona uma saída desse lugar subalternizado. A professora indiana Gayatri Chakravorty Spivak em seu livro Pode o Subalterno Falar, considera:

O subalterno não pode falar. Não há valor algum atribuído à "mulher" como um item respeitoso nas listas de prioridades globais. A representação não definhou. A mulher intelectual tem uma tarefa circunscrita que ela não deve rejeitar com um floreio. (SPIVAK, 2010, p. 126 , grifo da autora) 
Seguindo o pensamento de Spivak, observamos que Maria Tereza assume a escrita como uma forma de enfrentamento, elabora um discurso sobre seu estar no mundo, sobre suas condições de vida e sobre sua ancestralidade. Ela reverte, com sua escrita, este lugar de subalternidade e passa ao da intelectualidade, carregando consigo as marcas dessa subalternidade e promovendo a escuta de sua voz que, como dito por Spivak, não poderia ser ouvida como tal. Ninguém é subalterno, alguns estão neste lugar, são subalternizados. Por isso, neste ensaio Spivak irá dizer da importância do intelectual, neste caso da mulher negra, dar voz às suas iguais, sendo preciso que elas sejam agenciadas e não representadas.

Neste âmbito vemos a subjetividade de Tereza revelada por sua literatura. Esse fazer estético expande a noção de cultura e de sociedade, e revela aquilo que não está dito no cânone, mas que faz parte da construção social do país. A literatura de Tereza revela uma escrita que mostra, sobretudo, outra forma de falar e de escrever, forma essa que mistura vida e escrita, da qual reverberam vozes de resistência e luta que narram a transformação gerada pela vivência de dor, angústia, alegria e superação.

Essa é a escrevivência de Maria Tereza. Escrevivência é um termo cunhado por Conceição Evaristo. Para a escritora mineira o neologismo "escrevivência": escrita + vivência, é o termo adequado para falar de uma escrita sobre si que revela mais do que um "eu". É também uma tomada de consciência e uma forma de assumir o poder e desmistificar o que é dito sobre a mulher negra a partir de uma visão dominadora:

Assenhoreando-se "da pena", objeto representativo do poder falocêntrico branco, as escritoras negras buscam inscrever no corpus literário brasileiro imagens 
de uma autorrepresentação. Surge a fala de um corpo que não é apenas descrito, mas antes de tudo vivido. A escre(vivência) das mulheres negras explicita as aventuras e as desventuras de quem conhece uma dupla condição, que a sociedade teima em querer inferiorizada, mulher e negra (EVARISTO, 2000, p. 204).

Essa definição, como afirma Marcos Fabrício Lopes da Silva, "culmina numa atitude de emancipação epistemológica e performática a partir de uma articulação entre ficção e história." (SILVA (2013) apud CÔRTES, 2016, p.51). Ao cunhar o termo, Evaristo retoma sua trajetória, entrelaçada a uma vivência com a leitura e a própria escrita. Uma relação que é construída no seio familiar, através da audição de histórias lidas à luz de velas na infância belorizontina, ou que lia em livros emprestados pelas patroas das mulheres de sua família. E era esse o incentivo das que vieram antes dela. Assim, afirma: "Gosto de dizer ainda que a escrita é para mim o movimento de dança-canto que o meu corpo não executa, é a senha pela qual eu acesso o mundo." (EVARISTO, 2007, p.2). É, por fim, uma expressão estética literária adotada por mulheres negras com o intuito de combater seu lugar de subalternidade.

A aproximação do termo com a literatura de Tereza é pertinente por nos apresentar uma escrita que capta toda a essência da experiência do corpo negro feminino, seja ao criar neologismos com marcas fortes de oralidade, seja ao buscar, na ancestralidade, um modo de criar um futuro que expande o processo de condução da vida.

Maria Tereza nos apresenta, através de seus poemas, um jogo estabelecido entre passado, presente e futuro. $\mathrm{O}$ passado é alimentado pelos saberes de ancestrais, tendo como origem de sabedoria o Baobá, árvore que, segundo a mitologia yoruba, 
fecunda a terra e liga o mundo natural ao sobrenatural e guarda as histórias mais antigas. Já o presente é exuberância e resistência, assim o jogo passado e presente, terá como resultado um futuro que será afro, será negro, como vemos no poema abaixo:

\section{Rosa Preta}

Eu que não sou filha da regra exata

Eu que não sou filha do acaso puro

Eu é que afrorústica brasileira

Atento quando o tema é pensamento

Quando esse fluxo mensal poético

Inunda meu sistema nervoso

Neste corpo cheio de poros sei muito bem do meu osso

Sou rosa negra, quase parente do cáctus

Existo em exuberância e persistência

Minhas raízes se ramificam frutoflorificantes

Donde vim, donde vim sim, Frutoflorificantes

No baobá que pronde vou, fui e vim.

(TEREZA, 2007, p. 33)

Maria Tereza, além de captar toda essência da escrevivência, parece-nos ter consciência dela ao escrever, como se vê nesse poema. Em sua escrita não existe regra exata. Por outro lado, sua escrita não é criada com base no acaso puro, há uma consciência do fazer literário que evidencia que a poetisa fala do processo de escrita no poema e se organiza em seus versos como escrita de uma Rosa Preta, mulher preta, herdeira da diáspora africana - afrorústica - sempre atenta à poesia que reverbera da sua subjetividade.

E embora carregue consigo seu passado, sua obra é parte de um futuro que se sabe mais negro, se veste de pensamento e de poesia e põe para fora o "fluxo poético". Com isso "Surge a fala de um corpo que não é apenas descrito, mas antes de tudo vivido" (EVARISTO, 2000, p. 204). Sua ancestralidade 
é a base para que sua vida, poema e escrita ganhem forças para ser uma rosa preta, projeta um novo olhar sobre o presente e, consequentemente, sobre o futuro.

O poema em prosa, "Presente da Mãe", desenha de forma ainda mais nítida esta relação com a escrevivência, pois narra uma história de infância na qual a menina desejava um bolo vermelho de presente de sua mãe. Não atendendo à sua expectativa, acaba por lhe dar um bolo branco com apenas um morango. Seu presente é, na verdade, um caderno com folhas vermelhas, dessa maneira ela descobre a escrita e entende que aquele é o melhor presente que sua mãe poderia lhe dar.:

Quando eu tinha oito anos eu gostava muito de fazer bolo de terra no quintal da minha casa. Eu brincava de ser escultora e fazia uns bolos bem redondos, de vários tamanhos e cheios de velas, daquelas velas bem fininhas que parecem palitos. Só que eu não acendia as velinhas porque o vento apagava o fogo e minha mãe vivia espiando lá da janela da cozinha. Minha mãe é muito legal, um dia eu perguntei se ela faria um bolo vermelho, vermelho da cor da terra do quintal pra gente comer. Ela disse que sim, quando chegou o comecinho da noite ela me chamou dizendo que tinha uma surpresa! Eba!!! Pensei que era o bolo vermelho. Não era. Ela tinha feito um bolo branco e sem recheio... Tinha só um morango em cima... E não era muito gostoso. Mas a surpresa era outra coisa! Minha Mãe tinha trazido um presente! Era um embrulho bem grande e esquisito. Fui pro meu quartinho abrir o presente, acendi a luz, desembrulhei o pacote e o quarto ficou todo fascinante e brilhante: um caderno bem grosso recheado com folhas de papel de seda vermelhas! (TEREZA, 2007, p.15)

O presente é a possibilidade de ter contato com a escrita. Uma escrita em papel de seda, que remete ao delicado da folha e à força da cor vermelha. $\mathrm{O}$ presente traz luz e fascínio à vida da garota. Ao esperar apenas o que comer, a menina recebe um 
"alimento" muito mais duradouro. A vida narrada no poema e na obra como um todo - em vários momentos nos confunde na definição se o que se conta é uma história ou ficção. Este presente emblemático e significativo vem da Mãe, sua ancestre, que repassa seu conhecimento e demonstra a importância de se alimentar uma história. Esse foi também o modo como Conceição Evaristo foi alimentada, assim como outras escritoras negras que encontram em sua ancestralidade sentido para escrever e propagar, à sua maneira, as histórias que lhes foram contadas. Nesse sentido, observamos o alerta de Evaristo: "nenhum episódio pode ser lido tal como aconteceu; na escrita tudo se modificou. Quem conta um conto inventa um ponto e quem recria uma história a partir do real cria outra realidade para a história recriada". (EVARISTO, 2014 apud SANTOS, 2018, p.34)

Este poema, "Presente da Mãe", deu origem ao livro Vermelho, uma obra publicada em 2009, pela editora 34. O livro tem ilustrações do arquiteto e ilustrador chileno, Andrés Sandoval. Trata-se de uma autobiografia e confirma a relação da artista com a escrita desde a infância. Outro ponto reafirmado através das páginas vermelhas do livro é como Tereza sempre estabeleceu uma relação forte com o seu corpo, deixando-o a serviço de sua arte. São falas que aparecem no prefácio: “(...) estudou música, dança e teatro, e tomou parte em diversos espetáculos que tematizam a cultura negra."

A escrevivência de Maria Tereza apresenta o caminho revelador de uma ancestralidade. É a expressão de uma voz silenciada. Que vem "pelas vias" onde não "havia sinais", porém, "durante a vinda, vim vestindo caras! Caras de mulher" (TEREZA, 2007, p. 53). Este caminho foi percorrido antes por 
Carolina Maria de Jesus, Conceição Evaristo, Cristiane Sobral, entre outras. É possível identificar essa ancestralidade ao lermos as maiúsculas gritantes do poema, Brasileira Gigante:

Brasileira Gigante

A VIDA NÃO USE RUGE, FERA RI E RUGE

PARECE QUE O TEMPO URGE

NÃO SEI SAMBAR E TENHO MILHÕES DE OUTROS ENCANTOS!

CONTRA OLHO GORDO USO COLÍRIO DIET, TRABALHO!

SOB A LUZ DA LUA MUNDANA EU VOU QUE VOU

CAMINHANDO NO ASFALTO ELABORO MINHAS OFERENDAS

RECONHEÇO O QUE É DE FIRMEZA

SÃO BENEDITO, SANTO DE PRETO

BEBE CACHAÇA, MAMA NO PEITO

SÃO BENEDITO, SANTO DE PRETO

BEBE CACHAÇA, MAMA NO PEITO

MULHERES NEGRAS ME CRIARAM, MULHERES NEGRAS ME ENSINARAM

TIJOLO POR TIJOLO CONSTRUINDO UMA NOVA TRAMA

DIA POR DIA CULTIVAR A SAPIÊNCIA

DNA DE NEGRA CONTÉM MALEMOENCIA

TODA CRIANÇA TRAZ NO LADO ESQUERDO A BEM QUERENÇA

SOU BRASILEIRA GIGANTE, SOU BRASILEIRA GIGANTE!

(TEREZA, 207, p. 21)

Essa proposição de brincar com as palavras, de explorálas em seus significados e sentidos, extraindo delas outros significados, se estende às palavras que ela cria, neologismos, novos verbos de fácil absorção e entendimento que, porém, apresentam uma ampla significação, como as palavras aqui já 
usadas: afrorústica, negrices, frutoflorificantes e quilombizara. Ainda outras como: ressambando e corpa, título do poema que se segue:

\section{Corpa Negra}

Corpa Negra tivera a vida como presente Na labuta, suava de tanto nascer todo dia Chorou todas as lágrimas do mundo, cansara de rios de sangue

Cantara de tanto sofrer várias línguas

Multiplicara milhões de vezes os peixes e as bocas Assimilara ervas, árvores, credos, pedras e céus azuis Inspira sempre o ar renovando sapiência

Horroriza-se ante a qualquer tipo de açoites que ainda são

Parira amores e dores

Mesmo que grandes e pequenas nações desumanizadas Demoradamente a cada demora três centenas de anos Morreria mais que mil vezes e ainda agora resistia Trocou aquilo por isso e quilombolizara até hoje Banhou-se por horas a fio, perdoou-se de ranços, renomeou-se

Chegou aqui.

(TEREZA, 2007, p. 87). 


\section{Figura 1}

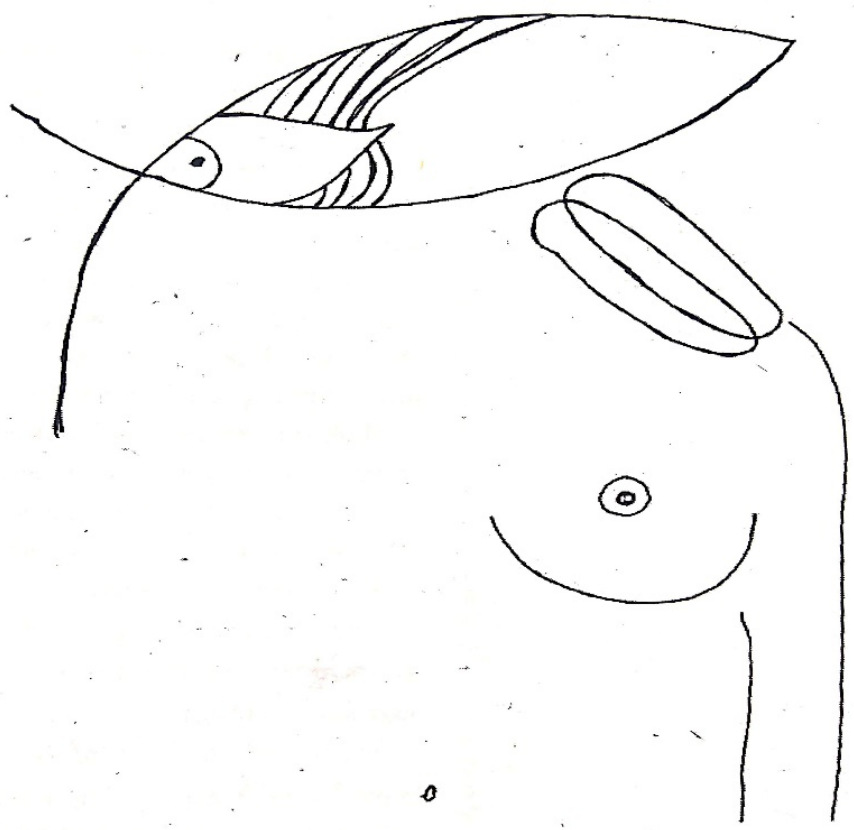

CS Scanned with

Fonte: TEREZA, 2007, p. 86.

Poema e imagem nos apresentam um novo corpo. Corpo que chegou até aqui e está renomeado, reinventado e se coloca em constante movimento. Esta Corpa,ainda não parou. Como a imagem nos conta pelos seus símbolos circulares, traços sem finalização e olhos na cabeça e no coração - um olho no seio, outro na imagem superior-, ela está ainda em construção. $\mathrm{Na}$ imagem vemos um corpo que tem um olhar que não parece ter fim, olha para o infinito e, como ele, não se encerra. Um corpo de mulher preta que, como nos diz o poema, já não é mais nomeado no masculino. Ou seja, é uma corpa que representa várias mulheres que trocaram "aquilo" - uma vida imposta, um corpo 
que não era seu e não seguia seus desejos - por isso: aquilombarse. Assim, "perdoou-se de ranços".

Sobre esse poema, "Corpa Negra", Terezinha Taborda Moreira irá pensar na predominância do pretérito. Sua reflexão fortalece a perspectiva da continuidade:

A predominância do pretérito sugere que a existência de Corpa Negra pode ser caracterizada pelo encadeamento de suas ações num movimento contínuo, geradas que são por uma dinâmica que a coloca em movimento perpétuo de transformação. Comprova isso o fato de o pretérito também permitir pontuar ações iniciadas no passado, mas ainda não concluídas: "suava de tanto nascer todo dia”. (MOREIRA, 2020, p. 8)

Essa continuidade proposta pelo último poema do livro Negrices em Flor é um alento para corpos diaspóricos que, como dito na epígrafe deste texto, são partes que se juntam para retransmitir o primeiro toque. É continuar o movimento do corpo/ vida, com muita força de resistência. Ao persistir em nascer todo dia essa corpa oferece, a corpas semelhantes, possibilidades de renascimento. Ainda que sofridos os caminhos, a poesia aponta para novas possibilidades, outras formas de fazer a os movimentos da vida. Com isso, observar os outros lados que essa existência pode produzir, como nos mostra o poema Ir Ver:

Ir ver

Ir ver o outro lado de si

Cantar até o canto ser encanto

Rolar as escadas e ladeiras do próprio pranto

Atravessar mundos, harmonizar sistemas

A outra face dura tua também tua muda

Pedir ajuda à ciência e ao santo

Recuar,

Deixar vir as crias, ouvir espumas do mar

Construir alicerce bem formado 
No poço profundo do mundo não cabe todo mundo

E lá quem sabe não é um bom lugar

Guerrear só quando.

(TEREZA, 2007, p. 16)

E é neste movimento de ir ver, é na ajuda que pede à ciência e ao santo, que Maria Tereza constrói sua obra. Sua biografia é um corposolo expresso através de suas escrevivências e negrices. E nesta manifestação não solitária abre espaço às identificações. Sua biografia é o seu legado, seus livros, sua forma de desenhar poemas com palavras e traços, verso e prosa. É ritmo, pulsão, memória, corpo, cadência melodiosa e malemolência gritada ou falada ao pé do ouvido, como quem nos dá uma piscadela e diz: “Oi, eu estou aqui!”. E é, ainda, uma biografia que nos anuncia: “serei breve mas não sucinta." (TEREZA, 2007, p.28)

\section{Referências}

CÔRTES, Cristiane. Diálogo sobre escrevivência e silêncio. In: DUARTE, Contância Lima; CÔRTES, Cristiane; PEREIRA, Maria do Rosário A. (ed). Escrevivências: Identidades, gênero e violência na obra de Conceição Evaristo. Belo Horizonte: Idea, 2016 p.51-60.

EVARISTO, Conceição. Gênero e Etnia: uma escre(vivência) da dupla face. In: MOREIRA, Nadilza Martins de Barros; SCHNEIDER, Diane (ed.). Mulheres no mundo, etnia, marginalidade e diáspora. João Pessoa: Idéia, 2005. P. 201212.

FANON, Frantz. Peles negras, máscaras brancas. Tradução de Renato da Silveira. Salvador: EDUFBA, 2008.

JESUS, Maria Tereza Moreira. Ruídos. São Paulo: Com Arte, 2002. 
Maria Tereza Moreira de Jesus (1974-2010). A atriz negra que se lançou em alto-mar. Da Redação. São Paulo, sexta-feira, 30 de abril de 2010. Folha de São Paulo. Caderno "Cotidiano". Disponível em: https://www1.folha.uol.com.br/fsp/cotidian/ ff3004201025.htm. Acesso em 25 de setembro de 2017.

MOREIRA, Terezinha Taborda. Uma poética do inacabamento: a escrita literária de Maria Tereza. Aletria: Revista de estudos de Literatura, 30(2), 39-58. https://doi.org/10.17851/23172096.30.2.39-

58.REIS, Mauricio de Novais e ANDRADE, Marcilea Freitas Ferraz de. $\mathrm{O}$ pensamento decolonial: análise, desafios e perspectivas.): Revista Espaço Acadêmico, v. 17 n. 202 , março de 2018.

SANTOS, Mirian Cristina. Intelectuais negras: prosa negrobrasileira contemporânea. Rio de Janeiro: Malê, 2018.

SILVA, Jane Quintiliano Guimarães; MOREIRA, Terezinha Taborda. Escrita e Perfomance. SCRIPTA, Belo Horizonte, v. 23, n. 47, p. 7-10, $1^{\circ}$ quadrimestre de 2019.

SPIVAK, Gayatri Chacravorty. Pode o subalterno Falar ? Tradução de Sandra Regina Goulart Almeida: Marcos Pereira Feitosa; André Pereira. Belo Horizonte: Editora da UFMG, 2010. TEREZA, Maria. Negrices em Flor. São Paulo: Edições Toró, 2007.

TEREZA, Maria. Vermelho. São Paulo: Editora 34, 2009. 